\section{CASE OF PERForating ULCER OF THE} STOMACH : PERITONITIS : DEATH.

TO THE EDITOR OF THE PROVINCIAL MEDICAL AND

SIr, SURGICAL JOURNAL.

Should the following case appear to possess any interest, perhaps you will kindly give it a place in your valuable Journal.

On the evening of the 30th of June, I attended a young woman, aged 19 , who had been suddenly seized that afternoon, after a long walk, with violent pain in the abdomen. She had previously enjoyed tolerable nealth, though occasionally the subject of dyspepsia, and had followed her usual employment in the factory, until the day before ber illness. I found her on the bed, almost bent double with excruciating torture in the abdomen, and unable to change her position withont increase of suffering; there was extreme tenderness on pressure, with violent sickness; the bowels had not been relieved for two days; the tongue had a red and glazed appearance, and the pulse was hard and full.

Taking all the circumstances of the case into consideration, the excruciating pain increased on pressure, the tension of the abdomen, and the state of the pulse, I considered myself justified in using the lancet; blood was drawn to the extent of eight ounces only, but with marked relief, for she could in a few minntes lie down in bed or change her position without increasing the pain. I ordered a large injection to be administered, and gave her a bolus with calomel and opium, to be followed by a cathartic mixture; the bowels were to be fomented with warm water, and afterwards covered with a large bran poultice. I left her apparently much relieved, and heard no more of her until the next morning about six o'clock, when I was hastily called to her bedside, alas, only to find her in a state of complete collapse, and to feel assured that leath was rapidly advancing. Injections with turpentine were again administered, and stimulants, but without avail ; she died about nine o'clock the same morning. The mind continued calm and composed to the last.

A post-mortem examination of the body was made the following day, and on opening the cavity of the abdomen the nature of the fatal illness at once became appurent. The peritoneum was inflamed most extensively, and the contents of the stomach were evacuated into the cavity, mixed with an abundance of serum, shreds of lymph, and a considerable quantity of pus. So rapid had been the change, that many of the patches of inflammation were already running into ulceration. On examining the stomach, a circular aperture was discovered, with hard and cartilaginous edges, (large enough to admit the stem of a tobaccopipe,) abore the pyloric ortice, the organ appeared otherwise healthy, with the exception of the thickened and indurated portion, which scarcely exceeded an inch in circumference. Is it not somewhat singular, that nature had not, in this case, made some attempt by the process of adhesive inflammation, to prevent the fatal lesion? I am also at a loss to conceive why, under the circumstances, the patient should have experienced relief from the loss of blood.

Believe me, Sir,

Your faithful servant,

EDWARD YOUNG, M.R.C.P., \&c,, Dublin. Btlper, July 4, 1845.
CASE OF INGUINAL HERNIA : EMPLOYMENT OF BELLADONNA OINTMENT: REDUCTION.

By A. C. Gall, Esq., Surgeon, Ripley.

July 14th, 1845. S. P., aged 55, the wife of a labourer, has for several years had an inguinal hernia, which has frequently descended, but she has always hitherto easily replaced it.

This morning it has descended much more than usual, and has not yielded to frequent attempts at reduction. Upon examination, I found a heruia of considerable size, occupying the left inguinal canal and labium pudendi. The taxis applied steadily for half an hour produced no effect. I had her removed home, giving her some belladonna ointment to apply over the neck of the hernia. Upon visiting her, about three hours afterwards, I found the heruia apparently in the same smate; but upon again applying the taxis, in the same manner as before, reduction was very readily affected.

- Having seen belladonna frequently efficacious in relieving spasmodic stricture, (a practice I believe, originating with the late $\mathrm{Mr}$. Tyrrell,) I am the more disposed to think it was of essential service in this case.

After repeated trials, I am satisfied the same remedy has a good effect in cases of dystocia from rigidity of the os and cervix uteri. The manner of applying it has been as an ointment, composed of one part of extract of belladonna, with three parts of a rather stiff wax ointment. Fire or six grains of this ointment applied to the circumference of the os uteri, generally causes speedy, and sometimes almost instantaneous, relaxation. \section{PROVINCIAL \\ Aedícal \& Eurgícal Journal.} WEDNESDAY, JULY 30, 1845.

We cannot allow the Annual Meetings recently held by the Branches of the Provincial Medical and Surgical Association to pass, without taking occasion to point out the great assistance afforded by these more local meetings towards carrying out the objects which the members of the Association bave in view. While the general meeting assembles together members from all parts of the country; and, to a certain extent, may thus be said to represent the sentiments of the whole body, these are perhaps more definitely and certainly ascertained, and the shades of difference on various questions of interest more clearly marked, in the local meetings, from the aggregate of which we may therefore be led to see more clearly the general tendency of the opinions of the profession, and to take a more comprehensive view of the relations of the whole.

In regard to objects of scientific enquiry, the general meetings have ever proved fruitful in the production of communications of great interest; and we would especially allude to the valuable papers of Mr. Ceely, on the Variold Vaecine; of 